\title{
Chronic and acute effects of solvents on central nervous system functions in floorlayers
}

\author{
KERSTIN EKBERG, ${ }^{1}$ L BARREGÅRD ${ }^{2}$ S HAGBERG ${ }^{2}$ AND GERD SÄLLSTEN ${ }^{2}$ \\ From the Department of Occupational Medicine, ${ }^{1}$ University Hospital, S-581 85 Linköping, and Department \\ of Occupational Medicine, ${ }^{2}$ Sahlgren Hospital, S-412 66 Göteborg, Sweden
}

ABSTRACT Floorlayers and age matched carpenters with long ( $\geqslant 20$ years) and short (5-10 years) occupational experience were compared with respect to chronic and acute neuropsychiatric, neuropsychological, and general health effects as related to different types of solvent exposure. An increased prevalence of neuropsychiatric illness occurred among floorlayers with long occupational experience, possibly caused by high levels of exposure which were present until the 1970s. The disease appears partly reversible since, at the time of the investigation, all had essentially recovered. Some impairment of performance in psychological tests was seen, however, in this group. Visuoanalytical impairment was associated with indices of exposure to glues based on alcohols whereas contact adhesives appeared more deleterious to perceptual functions. The increased prevalence of neuropsychiatric symptoms among the floorlayers was interpreted to reflect mainly acute effects on the central nervous system.

Several cross sectional studies on the effects of neurotoxic exposure, based on psychological testing, appeared during the 1970s. In most of these studies comparisons were made between the mean performance in exposed and unexposed groups or between groups with high and low exposure.

Many of the cross sectional studies have indicated impaired memory or learning ability in the exposed groups, impaired perceptual speed or accuracy, impaired psychomotor speed or manual dexterity, prolonged reaction time, or an increased variability in reaction time..$^{1-6}$ These impairments, however, may be a combination of both acute and chronic effects, as could be the case with the various symptoms reported in connection with solvent exposure, nausea, affect lability, concentration disturbances, and memory deficits, for example. ${ }^{7-9}$ The signs and symptoms are more or less in agreement with the so called psychoorganic syndrome, ${ }^{10}$ which is also characterised by a decreased ability to engage in abstract thinking. It has been associated with organic dysfunction in the central nervous system.

The exposure index most commonly used in cross sectional studies is the number of exposed years supplemented by measurements of the solvent concentrations in the working environment at the time of the

Accepted 13 May 1985 investigation. Correlations between indices of exposure and effects have shown no reliable doseresponse relation in studies on long term effects, although such associations are obtained in experimental studies of acute effects. ${ }^{11}$ Systematic associations between symptoms and performance impairments have not been reported either.

The selection of subjects into the studies has generally been guided by their availability. Selection according to predetermined criteria of the degree of exposure may be more efficient, since restrictions on exposure may make contrasts between acute and chronic effects possible. One strategy in a cross sectional design may be to select the subjects according to exposure criteria so that chronic effects are more or less likely to have developed. The experience is that an exposure period of about ten years or more is generally required for solvent induced neuropsychiatric disorders to develop. ${ }^{12}$

Epidemiological studies have indicated an association between neuropsychiatric disorders and different occupations with solvent exposure-for example, painting, ${ }^{1314}$ carpenting/cabinet making with exposure to lacquers and glues, ${ }^{15}$ and construction work. ${ }^{16}$ The rate ratios found have been around 2 , and consequently the attributable risk in these occupations is about $50 \%$-that is to say, every second individual in these occupations with a severe neuropsychiatric disorder might have developed the dis- 
order as a result of his exposure.

Floorlayers have previously been exposed to high concentrations of solvents. Measurements of solvent concentrations in the air during the early 1970s have shown hygienic effects, ${ }^{17}$ using the Swedish TLVs of 1982, from 1 to 7 for glues based on alcohols (ethanol/methanol) and for contact adhesives containing $75 \%$ solvents (benzine, acetone, toluene, and xylene) (unpublished measurements from the Swedish National Board of Occupational Safety and Health). These types of glues were commonly used during the late 1950 s and 1960s. During the 1970 s water based glues containing less than $5 \%$ solvents have gradually been introduced and the levels of exposure have substantially decreased.

Floorlayers with long and short durations of occupational experience respectively were considered to be interesting groups to study with respect to the development and the prognosis of chronic and acute solvent effects. Since their use of various types of glues is reasonably well defined, it was also considered possible to obtain individual indices for the various types of exposure.

\section{Material}

A questionnaire asking for the number of years worked in the occupation and the major professional tasks undertaken throughout their working life was posted to all 270 union registered floorlayers in the Gothenburg region, of whom $91 \%$ replied. The floorlayers were subgrouped according to the number of years in the occupation; parquet makers were excluded. Twenty five floorlayers with more than 20 years experience and 25 with 5-10 years experience were randomly drawn from their respective subgroups to take part in the study. From a list of all 3737 union registered carpenters in the same region six, matched for age, were drawn for each floorlayer. A questionnaire asking for number of years work experience and major tasks undertaken was also posted to these $\mathbf{3 0 0}$ men; $86 \%$ replied. For each selected floorlayer one carpenter was randomly drawn from among those who filled the criteria of similar age ( \pm 2 years), number of years experience ( \pm 5 years), and having not worked with solvents.

Subjects with diseases not related to their work, but possibly having effects on the central nervous system such as diabetes, epilepsy, or severe head trauma with lengthy unconsciousness, were excluded and replaced with new, randomly drawn subjects from the same subgroup.

The mean age was 46 (SD 7 years) in the two groups with long (mean 29 years, SD 6 years) work experience and 28 (SD 4 years) in the two groups with short (mean 9 years, SD 3 years) work experience. All were $\overline{\bar{a}}$ men, active in their professions.

\section{Methods}

\section{EXPOSURE}

Each subject completed a questionnaire and was inter- $\frac{\bar{C}}{0}$ viewed by an occupational hygienist about their use of $\frac{\overline{\bar{p}}}{\overline{\frac{1}{5}}}$ glues during different periods of their professional $\stackrel{\square}{\Omega}$ career. The glues were divided into the following cat- 0 egories: glues based on alcohols, contact adhesives ${ }^{\infty}$ with a high content $(75 \%)$ of organic solvents, and $\vec{\circ}$ water based glues. The information was used to calcu- $\vec{\overrightarrow{ }}$ late the exposure indices based on the number of litres $\stackrel{\omega}{\omega}$ of each type of glue used a day.

Measurements of the degree of solvent exposure of $\frac{\mathbb{D}}{3}$ five subjects were made at four workplaces using Sipin pumps operating at $50 \mathrm{ml} / \mathrm{min}$ and SKC charcoal î tubes. The charcoal tubes were placed in the breathing $\overrightarrow{0}$ zone and changed at such time intervals that they provided at least two long term samples a day for each 은 person for calculating time weighted averages (TWA). Several 15 minute samples were also taken: The ${ }^{T}$ solvents on the charcoal tubes were desorbed with $\frac{\mathbb{O}}{7}$ carbon disulphide and analysed with gas liquid chromatography. ${ }^{18}$

HEALTH INTER VIEW AND MEDICAL EXAMINATIO\& Information concerning previous and present heal was collected with emphasis on disorders related the central nervous system. All the subjects were inte viewed by an occupational physician. They also completed questionnaires that included sections on past and present symptoms and diseases, tobacco smoking, and the use of alcohol. One of the questionnaires, with special emphasis on neuropsychiatric symptoms, has previously been validated on groups exposed to neurotoxic substances and on unexposed groups. ${ }^{19}$

The physician performed a general medical and neurological examination. Blood (for sedimentation rate and haemoglobin) and urine (for screening for protein, glucose, and blood) samples were also taken. The forced vital capacity and forced expiratory volume in one second were measured with a calibrated spirometer (Vitalograph).

PSYCHOLOGICAL TESTS

A battery of 10 psychological tests encompassing measurements of verbal ability (synonyms), reasoning (figure classification), spatial ability (block design, unfolding), memory (Benton visual 1 etention), perceptual speed and accuracy (digit symbols, dots, identical numbers), and psychomotor ability (bolt, pins) was used. The test battery has been thoroughly described by Hogstedt et al. ${ }^{19}$ Testing was performed individually, except for a few paper and pencil tests carried out in groups of two or three. 
Table 1 Exposure indices for the groups of floorlayers

\begin{tabular}{|c|c|c|c|c|}
\hline \multirow[t]{2}{*}{ Exposure groups } & \multicolumn{2}{|c|}{$\geqslant 20$ years in profession } & \multicolumn{2}{|c|}{ 5-10 years in profession } \\
\hline & Mean & $S D$ & Mean & $S D$ \\
\hline No of years in the profession & 27 & 5 & 9 & 2 \\
\hline $\begin{array}{l}\text { Glue based on ethanol/methanol: } \\
\text { Years }>11 / \text { day } \\
\text { Years } \geqslant 101 / \text { day } \\
\text { Total dose (years } \times 1 / \text { day) } \\
\text { Average dose (total dose/professional years) }\end{array}$ & $\begin{array}{r}17 \\
14 \\
357 \\
13\end{array}$ & $\begin{array}{r}6 \\
6 \\
204 \\
6\end{array}$ & E & $\bar{z}$ \\
\hline $\begin{array}{l}\text { Contact adhesives ( } 75 \% \text { solvents): } \\
\text { Years (used this glue) } \\
\text { Years } \geqslant 51 / \text { day } \\
\text { Total dose (years } \times 1 / \text { day) } \\
\text { Average dose (total dose/professional years) }\end{array}$ & $\begin{array}{r}21 \\
6 \\
71 \\
3\end{array}$ & $\begin{array}{r}7 \\
7 \\
57 \\
2\end{array}$ & $\begin{array}{l}9 \\
0 \\
8 \\
1\end{array}$ & $\begin{array}{r}2 \\
0 \\
10 \\
1\end{array}$ \\
\hline
\end{tabular}

\section{Results}

\section{EXPOSURE}

The indices of exposure were calculated from the quantities of alcohol based glues and contact adhesives used by each subject during his years at work (table 1). Floorlayers with less than 10 years in the profession-that is, those who started in the profession in the late 1970s-had rarely, if ever, used alcohol based glues. This index of exposure was therefore calculated only for floorlayers with long experience (more than 20 years in the profession).

Floorlayers with at least 20 years in the profession had used large amounts (20-30 I a day) of alcohol based glues during the 1950s and 1960s. Measurements from the early 1970s show exposure levels around 1 if the glues contained only ethanol and up to
7 (hygienic effects) when both ethanol and methanol were present. During the 1970 s water based glues were introduced on to the market.

During the 1950s and 1960s about 5-10 1 a day of contact adhesives containing $75 \%$ solvents were used by the floorlayers. Hygienic effects between 4 and 7 were obtained in measurements made in the 1970s. During the 1970s the quantities used diminished, and at the time of the present study the floorlayers used $0 \cdot 2-11$ of contact adhesives a day.

Measurements of present solvent exposure show a hygienic effect below 0.5 as an average for eight hours (table 2), since water based glues are mostly used. Contact adhesives are used mainly for special purposes in bathrooms and laundries, and high levels of exposure may then still occur. Floorlayers nowadays, however, generally use a half mask with a charcoal

Table 2 Measurements of solvent exposure

\begin{tabular}{|c|c|c|c|c|c|c|}
\hline \multirow[t]{2}{*}{ Workplace products } & \multirow[t]{2}{*}{ Sampling time } & \multicolumn{5}{|c|}{ Concentration $\mathrm{mg} / \mathrm{m}^{3}$} \\
\hline & & Toluene & Acetone & Benzine & Ethyl acetate & Hygenic effect* \\
\hline \multicolumn{7}{|c|}{$\begin{array}{l}\text { Bathrooms; water based glues } \\
\text { and contact adhesives } \\
\text { Living rooms; water based } \\
\text { olues }\end{array}$} \\
\hline $\begin{array}{l}\text { glues } \\
\text { Living rooms; water based }\end{array}$ & 243 & - & - & 38 & - & 0.03 \\
\hline $\begin{array}{l}\text { glues } \\
\text { Bathrooms; water based glues }\end{array}$ & 246 & - & - & 25 & - & 0.02 \\
\hline $\begin{array}{l}\text { and contact adhesives } \\
\text { Laundry; water based glues } \\
\text { and contact adhesives } \\
\text { Short time samples; work with }\end{array}$ & $\begin{array}{l}259 \\
317 \\
309\end{array}$ & $\begin{array}{l}88 \\
40 \\
39\end{array}$ & $\begin{array}{l}\overline{29} \\
28\end{array}$ & $\begin{array}{l}88 \\
36 \\
31\end{array}$ & $\frac{101}{-}$ & $\begin{array}{l}0.5 \\
0.2 \\
0.2\end{array}$ \\
\hline $\begin{array}{l}\text { contact adhesives } \\
\text { Short time samples; work with }\end{array}$ & 15 & 757 & - & 765 & 830 & $4 \cdot 3$ \\
\hline $\begin{array}{l}\text { contact adhesives } \\
\text { Short time samples; work with }\end{array}$ & 15 & 221 & 58 & 167 & - & 1.0 \\
\hline $\begin{array}{l}\text { contact adhesives } \\
\text { Short time samples; work with }\end{array}$ & 15 & 217 & 63 & 189 & - & 1.0 \\
\hline $\begin{array}{l}\text { contact adhesives } \\
\text { Swedish TLV } 1982\end{array}$ & 15 & $\begin{array}{l}198 \\
300\end{array}$ & $\begin{array}{l}147 \\
600\end{array}$ & $\begin{array}{r}197 \\
1200\end{array}$ & $\overline{700}$ & $1 \cdot 1$ \\
\hline
\end{tabular}

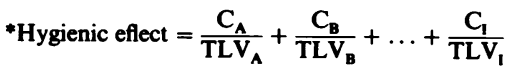

$\mathrm{C}_{\mathrm{A}}=$ Concentration $\mathrm{mg} / \mathrm{m}^{3}$ compound $\mathrm{A}$.

$\operatorname{TLV}_{A}=$ Threshold limit value, compound $A$. 
Table 3 Occurrence of neuropsychiatric illness in the groups with long professional experience

\begin{tabular}{|c|c|c|c|}
\hline & $\begin{array}{l}\text { Floorlayers } \\
(n=25)\end{array}$ & $\begin{array}{l}\text { Carpenters } \\
(n=25)\end{array}$ & \\
\hline $\begin{array}{l}\text { Depressive illness } \\
\text { Antidepressive medication } \\
\text { Treated at hospital for depression }\end{array}$ & $\begin{array}{l}7 \\
6 \\
4\end{array}$ & $\begin{array}{l}1 \\
1 \\
0\end{array}$ & $\begin{array}{l}p<0.05 \\
p<0.05\end{array}$ \\
\hline
\end{tabular}

filter during such tasks. Consequently their exposure might be even lower than the measurements suggest.

The carpenters' solvent exposure was negligible as compared with the floorlayers.

\section{HEALTH INTERVIEW AND MEDICAL}

EXAMINATION

The answers from the questionnaires were compared using a chi-squared test, although in cases when the expected frequencies were low, Fischer's exact probability test was used. ${ }^{20}$ The health screening data were compared with Student's $t$ test.

The medical interview and the results of the questionnaires showed a higher prevalence of depression in the floorlayer group with more than 20 years experience when compared with their controls (table 3 ). In the cases treated for depression symptoms had started after four to 31 years in the profession. At the time of the investigation none of the floorlayers had any signs of the illness and none used antidepressive medication.

A higher prevalence of current neuropsychiatric symptoms was reported by the floorlayers than by the carpenters. This was seen both in the interview and in the answers to the questionnaires. Floorlayers with more than 20 years in the occupation had on average 3.8 symptoms and their matched controls 0.5 symptoms $(\mathrm{p}<0.05)$ in the questionnaire. Floorlayers with less than 10 years in the occupation had on average 2.3 symptoms and their matched controls $1 \cdot 1$ symptoms $(\mathrm{p}<0.02)$. The groups differed most on

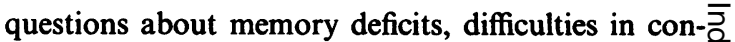
centration, and lability of affect. The groups did not 3 differ on reported head traumas with concussion or $\stackrel{\mathbb{Q}}{2}$ on alcohol consumption.

The medical and neurological examinations $\stackrel{\vec{\sim}}{\vec{s}}$ showed no differences between the floorlayers ando carpenters except that floorlayers with less than 10 음 years experience had a higher blood pressure than $\frac{\overline{\bar{p}}}{\bar{C}}$ their controls $(p<0.01)$. This group also had $a \Phi$ higher haemoglobin concentration than the carpen- 0 ters $(p<0.01)$, which was not explained by ${ }^{\text {c }}$ differences in smoking habits. The other laboratory. tests including spirometry did not differ between the $\overrightarrow{\vec{\omega}}$ groups.

\section{PSYCHOLOGICAL TESTS}

The mean performance of the groups on the psychological tests was compared with Student's $t$ test. in Floorlayers with long experience performed slightly $\vec{\circ}$ worse than their controls in the visuospatial block de- sign test $(p=0.05)$ but the groups did not differ in 은 mean performance on the remaining tests. Floor- layers with short experience performed less well than ${ }_{\overparen{\Phi}}^{\top}$ their controls only on the psychomotor bolt test $\left(p=\frac{0}{C}\right.$ 0.02) (table 4). Mean performance in the psycho-⿳亠丷厂 logical tests did not differ between those with and without previous antidepressive medication.

Partial correlation analysis, controlling for the@ effect of age, between the exposure indices and performance in the psychological tests, was performed. For the group of floorlayers with more than 20 years in the profession calculations were performed using three different indices of exposure; num- $\frac{\not}{\nabla}$ ber of occupational years (floorlayer years), total dose $\stackrel{\varrho}{\rightarrow}$ of contact adhesives, and total dose of glues based on $\overrightarrow{\overrightarrow{0}}$ alcohols. Since the floorlayers with less than 10 years in the profession had not used any appreciable quantity of glues based on alcohols this index was excluded in their analyses.

Performance on the block design test had a nega-

Table 4 Average scores on the psychological tests

\begin{tabular}{|c|c|c|c|c|c|c|c|c|}
\hline \multirow[t]{3}{*}{ Test } & \multicolumn{4}{|c|}{$\geqslant 20$ years in profession } & \multicolumn{4}{|c|}{$5-10$ years in profession } \\
\hline & \multicolumn{2}{|c|}{ Floorlayers } & \multicolumn{2}{|c|}{ Carpenters } & \multicolumn{2}{|c|}{ Floorlayers } & \multicolumn{2}{|c|}{ Carpenters } \\
\hline & Mean & $S D$ & Mean & $S D$ & Mean & $S D$ & Mean & $S D$ \\
\hline $\begin{array}{l}\text { Synonyms } \\
\text { Block design } \\
\text { Unfolding } \\
\text { Reasoning } \\
\text { Benton } \\
\text { Benton (faults) } \\
\text { Digit symbols } \\
\text { Identical numbers } \\
\text { Dots-speed } \\
\text { Bolt } \\
\text { Pins }\end{array}$ & $\begin{array}{r}19 \cdot 7 \\
25 \cdot 2 \\
27 \cdot 1 \\
20 \cdot 3 \\
6 \cdot 9 \\
4 \cdot 8 \\
43 \cdot 2 \\
88 \cdot 7 \\
738 \cdot 8 \\
22 \cdot 2 \\
28 \cdot 5\end{array}$ & $\begin{array}{r}4 \cdot 9 \\
5 \cdot 5 \\
7 \cdot 5 \\
3 \cdot 1 \\
1 \cdot 4 \\
2 \cdot 7 \\
7 \cdot 9 \\
14 \cdot 3 \\
115 \cdot 7 \\
4 \cdot 5 \\
3 \cdot 4\end{array}$ & $\begin{array}{r}19 \cdot 6 \\
28 \cdot 5 \\
29 \cdot 3 \\
21 \cdot 4 \\
7 \cdot 1 \\
4 \cdot 1 \\
42 \cdot 4 \\
84 \cdot 2 \\
766 \cdot 0 \\
22 \cdot 0 \\
27 \cdot 9\end{array}$ & $\begin{array}{r}5.6 \\
6 \cdot 3 \\
5 \cdot 6 \\
4 \cdot 5 \\
1.4 \\
2 \cdot 2 \\
11.9 \\
15 \cdot 8 \\
166.9 \\
4 \cdot 5 \\
3.6\end{array}$ & $\begin{array}{r}18 \cdot 3 \\
28 \cdot 4 \\
29 \cdot 7 \\
22 \cdot 7 \\
7 \cdot 5 \\
3 \cdot 4 \\
52 \cdot 3 \\
89 \cdot 1 \\
771 \cdot 0 \\
23 \cdot 8 \\
29 \cdot 3\end{array}$ & $\begin{array}{r}3 \cdot 1 \\
4 \cdot 5 \\
5 \cdot 2 \\
3 \cdot 0 \\
1 \cdot 5 \\
2 \cdot 5 \\
8 \cdot 7 \\
13 \cdot 4 \\
127 \cdot 5 \\
3 \cdot 6 \\
3 \cdot 4\end{array}$ & $\begin{array}{r}18 \cdot 3 \\
29 \cdot 9 \\
30 \cdot 7 \\
23 \cdot 4 \\
7 \cdot 3 \\
3 \cdot 6 \\
50 \cdot 6 \\
83 \cdot 2 \\
796 \cdot 0 \\
26 \cdot 2 \\
29 \cdot 6\end{array}$ & $\begin{array}{r}4 \cdot 5 \\
4 \cdot 0 \\
6 \cdot 1 \\
3 \cdot 3 \\
1 \cdot 3 \\
1.9 \\
8 \cdot 5 \\
10 \cdot 2 \\
118.5 \\
3.5 \\
3.8\end{array}$ \\
\hline
\end{tabular}


Table 5 Partial correlation coefficients (age controlled) between exposure indices and performance in psychological tests for all floorlayers $(n=50)$ and for floorlayers with at least 20 years experience $(n=25)$

\begin{tabular}{|c|c|c|c|c|c|c|}
\hline \multirow[t]{3}{*}{ Psychological test } & \multicolumn{6}{|c|}{ Exposure indices } \\
\hline & \multicolumn{2}{|c|}{ Floorlayers years } & \multicolumn{2}{|c|}{ Total dose; contact adhesives } & \multicolumn{2}{|c|}{ Total dose; alcohol based glues } \\
\hline & $A l l$ & $\begin{array}{l}\text { Long } \\
\text { experience }\end{array}$ & All & $\begin{array}{l}\text { Long } \\
\text { experience }\end{array}$ & All & $\begin{array}{l}\text { Long } \\
\text { experience }\end{array}$ \\
\hline $\begin{array}{l}\text { Synonyms } \\
\text { Block design } \\
\text { Unfolding } \\
\text { Reasoning } \\
\text { Benton } \\
\text { Benton (faults) } \\
\text { Digit symbols } \\
\text { Identical numbers } \\
\text { Dots-speed } \\
\text { Bolt } \\
\text { Pins }\end{array}$ & $\begin{array}{c}0.18 \\
-0 \cdot 29^{*} \\
-0.01 \\
-0 \cdot 10 \\
-0.02 \\
0.03 \\
-0.01 \\
-0.10 \\
-0.06 \\
0.34^{* *} \\
0.24^{*}\end{array}$ & $\begin{array}{r}0.29 \\
-0.15 \\
-0.04 \\
0.02 \\
-0.09 \\
0.13 \\
0.10 \\
0.05 \\
0.08 \\
-0.05 \\
0.07\end{array}$ & $\begin{array}{l}-0.11 \\
0.12 \\
0.21 \\
0.07 \\
-0.01 \\
-0.03 \\
-0.27^{*} \\
-0.23\left(^{*}\right) \\
-0.08 \\
0.24^{*} \\
0.22\left(^{*}\right)\end{array}$ & $\begin{array}{c}-0 \cdot 15 \\
0 \cdot 10 \\
0 \cdot 23 \\
0.17 \\
0.02 \\
-0 \cdot 13 \\
-0.49 * * \\
-0 \cdot 29\left(^{*}\right) \\
-0.16 \\
0.20 \\
0.21\end{array}$ & $\begin{array}{l}\bar{z} \\
\bar{z} \\
\bar{z} \\
\bar{z} \\
\overline{-}\end{array}$ & $\begin{array}{l}-0 \cdot 28 \\
-0 \cdot 39^{*} \\
-0 \cdot 29\left(^{*}\right) \\
-0 \cdot 34\left(^{*}\right) \\
-0 \cdot 34\left(^{*}\right) \\
0 \cdot 43^{*} \\
-0 \cdot 26 \\
-0 \cdot 04 \\
-0 \cdot 21 \\
-0 \cdot 43^{*} \\
0 \cdot 10\end{array}$ \\
\hline
\end{tabular}

${ }^{* *}=p \leqslant 0.01 ; *=p \leqslant 0.05 ;\left(^{*}\right)=0.05<p<0.10$.

tive association with the number of years worked when calculated for the whole group of floorlayers but performance on the psychomotor tests had, unexpectedly, a positive association with floorlayer years (table 5). This association disappeared when the group with short work experience was excluded from the analysis.

In the group with long experience the total dose of contact adhesives was negatively associated with performance on perceptual tests whereas the total dose of alcohol based glues was negatively associated with performance on visuospatial tests and visual memory and a psychomotor test (table 5). No systematic associations between the exposure indices and performance on psychological tests were obtained for the group with short experience.

The number of reported symptoms did not correlate with the exposure indices or with performance on psychological tests.

\section{Discussion}

Two groups of floorlayers with long ( $\geqslant 20$ years) or short (5-10 years) work experience were thoroughly investigated with respect to past and present exposure to organic solvents and their health and central nervous system function were compared with that of carpenters. All the subjects were active in their professions and hence there was no reason to suspect any severe clinical diseases.

The cross sectional design of the study causes difficulties in evaluating acute as compared with chronic effects of solvent exposure. Various experimental studies of the acute effects of isolated short term exposure to solvents have shown that short term exposure, even at low levels, has a negative effect on performance. ${ }^{11}$ Since, in most cross sectional studies, the exposed group has been unexposed for only a few hours or days before the investigation, acute and chronic effects may be confused and this would tend to overestimate the chronic health hazard. The subjects in the present study, however, were selected with regard to duration of exposure to make a differentiation between acute and chronic effects possible. If acute effects only were present both groups of floorlayers would be equally likely to suffer from them. It is unlikely that chronic effects would be seen in subjects with only 5-10 years in the job ${ }^{12}$ but such effects are conceivable in the group with at least 20 years in the profession. A drawback of the study is that the group with long experience may suffer from the healthy worker effect which would lead to an underestimation of the chronic health hazard.

The exposure history of the subjects and the measurements of present exposure levels indicate that solvent exposure was high up to the early 1970 s. Water based glues were then introduced and the present exposure levels correspond to a hygienic effect less than $0 \cdot 5$. Flooring in bathrooms and laundries when contact adhesives with high content of solvents are used may still give high levels of exposure, however.

The increased prevalence of neuropsychiatric illness in the floorlayer group with long exposure may be associated with the high levels of exposure during the 1950 s and 1960 s, since no other likely cause of the disease was shown. It also appears that the disease was partly reversible since, at the time of the investigation, all had essentially recovered. The negative associations obtained in the group with long professional experience between the exposure indices and performance in psychological tests, although weak, support the hypothesis that previous high levels of exposure, in particular to glues based on alcohols, has had some irreversible effects on the central ner- 
vous system.

The increased prevalence of neuropsychiatric symptoms in both floorlayer groups, as compared with the unexposed carpenters, may indicate that exposure even at levels below a hygienic effect less than 0.5 causes symptoms to develop. Since no performance decrements were seen in the group with short occupational experience, and since the symptoms and performance in the psychological tests were unrelated, the symptoms are likely to reflect acute adverse effects on the central nervous system. It is also possible that anxiety about the health effects of solvent exposure may make the floorlayers more observant of symptoms that are essentially normal. It may also be the case, however, that different mechanisms cause the development of symptoms and performance impairment respectively.

The results of the present study indicate that it may be possible to separate chronic and acute effects within a cross sectional design, provided that the studied groups are selected with great care and according to predetermined criteria with respect to their exposure to solvents. The results also indicate that it is possible to detect different effects on the central nervous system of different types of solvents. Although the negative associations between exposure to glues based on alcohols and visuoanalytical test performance are weak, they point to effects of these types of solvents that are in agreement with the association frequently obtained between excessive oral ethanol intake and impaired visuospatial performance (H Bergman, paper at conference on clinical implications of recent neurological findings, Boston, 16-18 May 1984). Exposure to contact adhesives appears to be most deleterious to perceptual functions. The results emphasise the importance of reducing exposure to neurotoxic solvents in those countries where alcohol based glues or contact adhesives are still widely used by floorlayers.

We are indebted to Professor Olav Axelson for his valuable comments on the manuscript.

This study was supported by grants from the Swedish Work Environment Fund, which is gratefully acknowledged.

\section{References}

${ }^{1}$ Elofsson SA, Gamberale F, Hindmarsh T, et al. Exposure to organic solvents. A cross-sectional epidemiologic investigation on occupationally exposed car and industrial spray painters with special reference to the nervous system. Scand $J$ Work Environ
Health 1980;6:239-73.

${ }^{2}$ Hane M, Axelson O, Blume J, Hogstedt C, Sundell L, Ydreborg B. Psychological function changes among house painters. Scand $J \mathbb{\mathbb { D }}$ Work Environ Health 1977;3:91-9.

${ }^{3}$ Hänninen H, Eskelinen L, Husman K, Nurminen M. Behavioural effects of long-term exposure to a mixture of organic solvents. Scand J Work Environ Health 1976;4:240-55.

${ }^{4} \mathrm{Knave}$ B, Anselm-Olson B, Elofsson S, et al. Long-term exposure to jet fuel. II. A cross-sectional epidemiological investigation on $\frac{\bar{\sigma}}{\bar{\omega}}$ occupationally-exposed industrial workers with special reference $\frac{}{\supset}$ to the nervous system. Scand J Work Environ Health ${ }_{\varnothing}^{\Phi}$ 1978;4:19-45.

${ }^{5}$ Lindström K, Härkönen H, Hernberg S. Disturbances in psychological functions of workers occupationally exposed to styrene. $\overrightarrow{0}$ Scand J Work Environ Health 1976;3:129-39.

${ }^{6}$ Lindström K, Wickström G. Psychological function changes $\overrightarrow{\vec{\omega}}$ among maintenance house painters exposed to low levels of or- $\omega$ ganic solvents mixtures. Acta Psychiatr Scand 1983;67, suppl 303:81-91.

${ }^{7}$ Hane M, Hogstedt C. Subjektiva symptom i yrkesgrupper som exponerats för lösningsmedel. Läkartidningen 1980;77:435-9.

${ }^{8}$ Husman K. Symptoms of car painters with long-term exposure to a mixture of organic solvents. Scand $J$ Work Environ Health 1980;6:19-32.

${ }^{9}$ Härkönen H. Relationship of symptoms to occupational styrene exposure and to the findings of electroencephalographic and $\mathrm{O}$ psychological examinations. Int Arch Occup Environ Health1977;40:231-9.

${ }^{10}$ Mayer-Gross W, Slater E, Roth M. Clinical psychiatry. 3rd ed. $\mathbb{O}$ London: Bailliere, Tindall \& Cassel, 1969.

${ }^{11}$ Gamberale F. Behavioural effects of exposure to solvent vapors. ำ Experimental and field studies. In: Adverse effects of environmental chemicals and psychotropic drugs. Amsterdam: Elsevier $\overrightarrow{0}$ Scientific Publ Co, 1976:111-33.

${ }^{12}$ Flodin U, Edling C, Axelson O. Clinical studies of psychoorgafic. syndromes among workers with exposure to solvents. $A m J$ K Med 1984;5:287-95.

${ }^{13}$ Axelson O, Hane M, Hogstedt C. A case-referent study neuropsychiatric disorders among workers exposed to solvents. Scand J Work Environ Health 1976;3:14-20.

${ }^{14}$ Mikkelsen S. A cohort study of disability pension and death among painters with regard to disabling presenile dementia as 으 an occupational disease. Scand $J$ Soc Med [suppl] $\overrightarrow{\hat{O}}$ 1980;16:34-43.

${ }^{15}$ Olsen J, Sabroe S. A case-referent study of neuropsychiatric disor- $-\frac{3}{\supset}$ ders among workers exposed to solvents in the Danish wood and furniture industry. Scand J Soc Med [suppl] 1980;16:34-49.

${ }^{16}$ Lindström K, Riihimäki H, Hänninen K. Occupational solvent $\widehat{O}$ exposure and neuropsychiatric disorders. Scand J Work Environ $\frac{\mathbb{\Phi}}{3}$ Health 1984;10:321-3.

${ }^{17}$ American Conference of Governmental Industrial Hygienists. Threshold limit values for chemical substances and physical agents - . in the workroom environment with intended changes for 1980. Cincinnati: ACGIH, 1980.

18 Taylor DG (manual coordinator). NIOSH manual of analytical methods. 2nd ed. Vol 1. Cincinnati: US Department of Health, 윽 Education and Welfare, National Institute for Occupational Safety and Health, 1977.

${ }^{19}$ Hogstedt C, Hane M, Axelson O. Diagnostic and health care aspects on workers exposed to solvents. In: Zenz C, ed. Devel-N opments in occupational medicine. Chicago: Medical Year Book Publishers, 1980.

${ }^{20}$ Siegel S. Nonparametric statistics for the behavioural sciences. NewNి York: McGraw-Hill, 1956. 